\title{
ABOUT AN APPROXIMATE METHOD TO SOLVE THE STATIC BOUNDARY VALUE PROBLEMS IN THE ISOTROPIC HARDENING ELASTIC-PLASTIC SOLID
}

\author{
${ }^{1}$ Ngo Thanh Phong, ${ }^{1}$ Nguyen Thoi Trung, and ${ }^{2}$ Nguren Phu Vinh \\ ${ }^{1}$ University of Natural Sciences, VNU, HCMC, \\ ${ }^{2}$ University of Industry, Hochiminh City
}

\begin{abstract}
The paper presents the theory, model, weak form, finite element method and return-mapping algorithm for the isotropic hardening elastic-plastic problem. Then applying the algorithm to numerically simulate a variety of plane strain problems.
\end{abstract}

\section{INTRODUCTION}

The plasticity theory has been researched in depth in recent decades. The approximate methods to solve the elastic-plastic problems are still topical and challenge researchers. The most difficult problem in elastic-plastic problems is to determine the yield surface which divides the problem domain into the elastic domain and the plastic domain. On the yield surface, the components of stress, strain, displacement have to be continuous. In the elastic domain, we obtain the elliptic equation system with 15 equations and 15 variables. In the plastic domain, with von Mises yield condition, Drucker axiomatics and combined yield law, we obtain the hyperbolic non-linear close equation system. In approximate methods to solve elastic-plastic problems, there are two noticed methods: the variational inequality method by Glowinski, Lions, and Tremolieres [6], and return-mapping method by Simo and Hughes [3]. In this paper, we use the latter.

In the isotropic hardening elastic-plastic model, the elastic range in the stress space is enlarged in both direction of tension and compression when the behavior of the material is in the isotropic hardening phase (Fig. 1, Fig. 2).

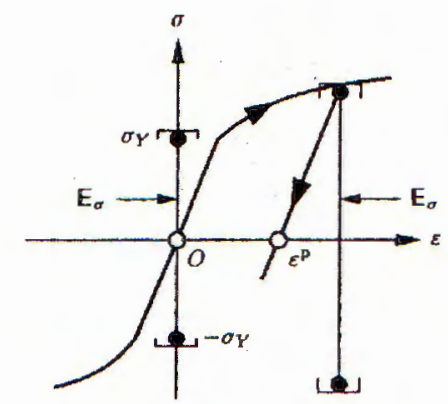

Fig. 1. The strain - stress relationship in isotropic hardening

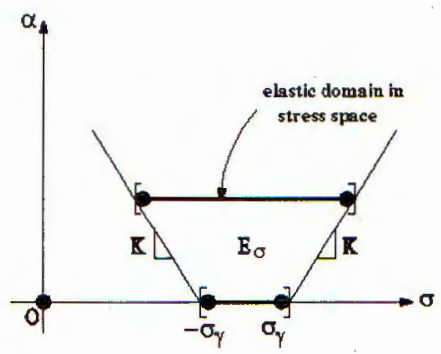

Fig. 2. The elastic range in the stress space is enlarged after yield flow 


\section{SUMMARY OF ISOTROPIC HARDENING ELASTIC-PLASTIC THEORY [3]}

We present the theory of infinitesimal strain in the Descartes orthotropic system $x_{i}$ ( $i=$ $1,2,3)$. We write tensors in indexes and use the summation law defending on Einstein's dumb index.

\section{a. The total strain}

$$
\epsilon_{i j}=\epsilon_{i j}^{e}+\epsilon_{i j}^{p},
$$

where $\epsilon_{i j}$ - tensor of total strain; $\epsilon_{i j}^{e}$ - tensor of elastic strain; $\epsilon_{i j}^{p}$ - tensor of plastic strain.

\section{b. Elastic stress - strain relationship}

$$
\sigma_{i j}=C_{i j k l}\left(\epsilon_{k l}-\epsilon_{k l}^{p}\right) \text {, }
$$

where $\sigma_{i j}$ - tensor of elastic stress; $C_{i j k l}$ - fourth-order elastic modulus tensor which is symmetric $C_{i j k l}=C_{j i k l}=C_{i j l k}=C_{k l i j}$ and positive definite $\xi_{i j} C_{i j k l} \xi_{k l} \geq \beta\|\xi\|^{2}$, where $\beta>0, \xi_{i j} \in R^{6},\|\xi\|^{2}=\xi_{i j} \xi_{i j}$.

c. Yield condition (von Mises yield criterion) with linear isotropic hardening

$$
f\left(\sigma_{i j}, \alpha\right)=\left\|s_{i j}\right\|-\sqrt{\frac{2}{3}}\left(\sigma_{\gamma}+K \alpha\right) \leq 0
$$

where $\sigma_{\gamma}$ - initial flow stress of the material; $\alpha \geq 0$ - internal hardening variable; $K$ hardening modulus

$$
\begin{gathered}
\left\|s_{i j}\right\|=\sqrt{s_{i j} s_{i j}} \text { with } s_{i j}=\sigma_{i j}-\frac{1}{3} \operatorname{tr}\left[\sigma_{i j}\right] \delta_{i j} \text { (tensor of deviator stress), } \\
\operatorname{tr}\left[\sigma_{i j}\right]=\sigma_{11}+\sigma_{22}+\sigma_{33} .
\end{gathered}
$$

d. Associative flow rule

$$
\dot{\epsilon}_{i j}^{p}=\Delta \gamma \frac{\partial f}{\partial \sigma_{i j}}
$$

where $\Delta \gamma \geq 0$ - slip rate.

e. Isotropic hardening law

$$
\dot{\alpha}=-\triangle \gamma \frac{\partial f}{\partial \alpha}
$$

\section{f. Kuhn-Tucker complementarity conditions}

$$
\Delta \gamma \geq 0, f\left(\sigma_{i j}, \alpha\right) \leq 0, \Delta \gamma f\left(\sigma_{i j}, \alpha\right)=0 .
$$

These conditions express the physical requirements that the stress must be admissible and plastic flow can take place only on the yield surface.

$$
\left\{\begin{array}{l}
f\left(\sigma_{i j}, \alpha\right)<0 \Rightarrow \Delta \gamma=0 \\
\Delta \gamma>0 \Rightarrow f\left(\sigma_{i j}, \alpha\right)=0
\end{array}\right.
$$




\section{g. Consistence condition}

$$
\Delta \gamma \dot{f}\left(\sigma_{i j}, \alpha\right)=0 \text { if } f\left(\sigma_{i j}, \alpha\right)=0 .
$$

These conditions express the physical requirements that when the stress is in the plastic range, the plastic flow can only continue to take place when the stress continues to persist on the plastic boundary $\dot{f}\left(\sigma_{i j}, \alpha\right)=0$, but if $\dot{f}\left(\sigma_{i j}, \alpha\right)<0$ (means unloading), the plastic flow will terminate.

$$
\left\{\begin{array}{l}
\triangle \gamma>0 \Rightarrow \dot{f}=0 \\
\dot{f}<0 \Rightarrow \Delta \gamma=0
\end{array}\right.
$$

\section{MODEL, WEAK FORM AND FINITE ELEMENT METHOD OF ISOTROPIC HARDENING ELASTIC-PLASTIC PROBLEM}

\subsection{Model and weak form}

Let $\Omega \subset R^{3}$ be a bounded domain with polygonal boundary $\Gamma$. Stress field $\sigma_{i j} \subset L^{2}(\Omega)$ and the volume force $f_{i} \subset L^{2}(\Omega)$ are related by the local quasi-static balance of forces

$$
\sigma_{i j, j}+f_{i}=0 .
$$

Displacement $u_{i}$ and the strain tensor $\epsilon_{i j}$ are related by the kinematic equation

$$
\epsilon_{i j}=\frac{1}{2}\left(u_{i, j}+u_{j, i}\right)
$$

In the elastic-plastic problem, when the stress $\sigma_{i j}$ hasn't yet reached the flow stress $\sigma_{\gamma}$ on the whole of bounded domain, it will exist a yield surface which divide the problem domain into the elastic domain and the plastic domain. In the elastic domain, the stress tensor $\sigma_{i j}^{e}$ and the strain tensor $\epsilon_{i j}^{e}$ are related by the Hooke law (2.2). In the plastic domain, the stress tensor $\sigma_{i j}^{p}$ is satisfied the yield condition (2.3), the velocity of the strain tensor $\dot{\epsilon}_{i j}^{p}$ and the internal hardening variable $\alpha$ are defined by associative flow rule (2.4) and isotropic hardening law (2.5). From the condition of balance of force and the condition of continuity of displacement, on the yield surface, we have

$$
\sigma_{i j}^{e}=\sigma_{i j}^{p} ; \quad u_{i}^{e}=u_{i}^{p} ; \quad \epsilon_{i j}^{e}=\epsilon_{i j}^{p} .
$$

On some closed subset $\Gamma_{D}$ of the boundary with positive length, we assume Dirichlet conditions while we have Neumann boundary conditions on the (possible empty) part $\Gamma_{N}$. With a surface force $g_{i} \subset L^{2}\left(\Gamma_{N}\right)$, we have

$$
u_{i}=\bar{u}_{i} \text { on } \Gamma_{D} \text { and } \sigma_{i j} n_{j}=g_{i} \text { on } \Gamma_{N} \text {. }
$$

In summary, in the elastic domain, with equations (3.1), (3.2) and (2.2), we obtain the elliptic equation system with 15 equations and 15 variables ( 6 stress components, 6 strain components and 3 displacement components). In the plastic domain, with equations (3.1), (3.2), (2.3), (2.4), (2.5) we obtain the hyperbolic non-linear close equation system with 17 equations and 17 variables $\sigma_{i j}, u_{i}, \epsilon_{i j}, \Delta \gamma, \alpha$. On the yield surface, the continuous condition of stress, strain, and displacement is satisfied. 
The elastic-plastic problem is then determined by the weak formulation. Seek $u_{i} \subset$ $H^{1}(\Omega)$ that satisfies $u_{i}=\bar{u}_{i}$ on $\Gamma_{D}$ that, for all $v_{i} \subset H_{0}^{1}(\Omega)=\left\{v_{i} \subset H^{1}(\Omega): v_{i}=0\right.$ on $\left.\Gamma_{D}\right\}$

$$
\iiint_{\Omega} \sigma_{i j}\left(u_{i}\right) \epsilon_{i j}\left(v_{i}\right) d v=\iiint_{\Omega} f_{i} v_{i} d v+\iint_{\Gamma_{N}} g_{i} v_{i} d s
$$

\subsection{Finite element method}

We consider a displacement $u_{n+1}$ of the elastic-plastic problem, which is stated as:

$$
R\left(u_{n+1}\right)=R\left(u_{n}+\Delta u_{n+1}\right)=F^{e x t}-F^{i n t}\left(u_{n+1}\right)=0,
$$

where $R\left(u_{n+1}\right)$ is the residual vector at $(n+1)^{\text {th }}$ iteration; $F^{\text {ext }}$ is the vector of applied forces; $F^{i n t}\left(u_{n+1}\right)=\bigwedge_{e=1}^{n} \iint_{\Gamma_{e}} B^{T} \sigma_{n+1} d \sigma$ is the global internal forces vector; $\bigwedge_{e=1}^{n}$ is the standard assembly operator.

From this equation, the incremental displacement $\Delta u_{n+1}$ is the solution of the simultaneously linear algebraic equations:

$$
\Delta u_{n+1}=-\left[K_{n+1}\right]^{-1}\left[F^{e x t}-F_{n+1}^{i n t}\left(\sigma_{n+1}\right)\right],
$$

where $K_{n+1}=\left.\bigwedge_{e=1}^{n} k_{e}\right|_{n+1}$ - global stiffness matrix; $\left.k_{e}\right|_{n+1}=\iiint_{B} B_{e}^{T} C_{n+1} B_{e} d v$ - element stiffness matrix; $C_{n+1}$ - consistent elastic-plastic modulus which is explained in detail in return mapping algorithm. The isotropic hardening elastic-plastic problem using von Mises yield criterion is presented by the return mapping algorithm combining with the finite element method as following: (to simplify the symbols, we don't write the index of tensor and vector in the algorithm).

\section{RETURN MAPPING ALGORITHM FOR THE ISOTROPIC HARDENING ELASTIC-PLASTIC MODEL [2], [3], [5]}

In the diagram, we have

$$
\begin{aligned}
& \kappa=\lambda+\frac{2}{3} G \text { - bulk modulus; } \\
& \lambda=\frac{2 G \nu}{1-2 \nu}-\text { Lame constant; } \\
& G=\frac{E}{2(1+\nu)}-\text { shear modulus; } \\
& E \text { - elastic modulus; } \\
& \nu \text { - Poisson factor; } \\
& u_{n} \text { - nodal displacement vector corresponding to the load vector } F_{n}^{\text {ext }} \text {; } \\
& \mathrm{I}=\left[\begin{array}{llllll}
1 & 1 & 1 & 0 & 0 & 0
\end{array}\right]^{T} \\
& \mathrm{II}=\left[\delta_{i j}\right], i, j=\overline{1,6} \text {; } \\
& \otimes \text { - tensor product. }
\end{aligned}
$$




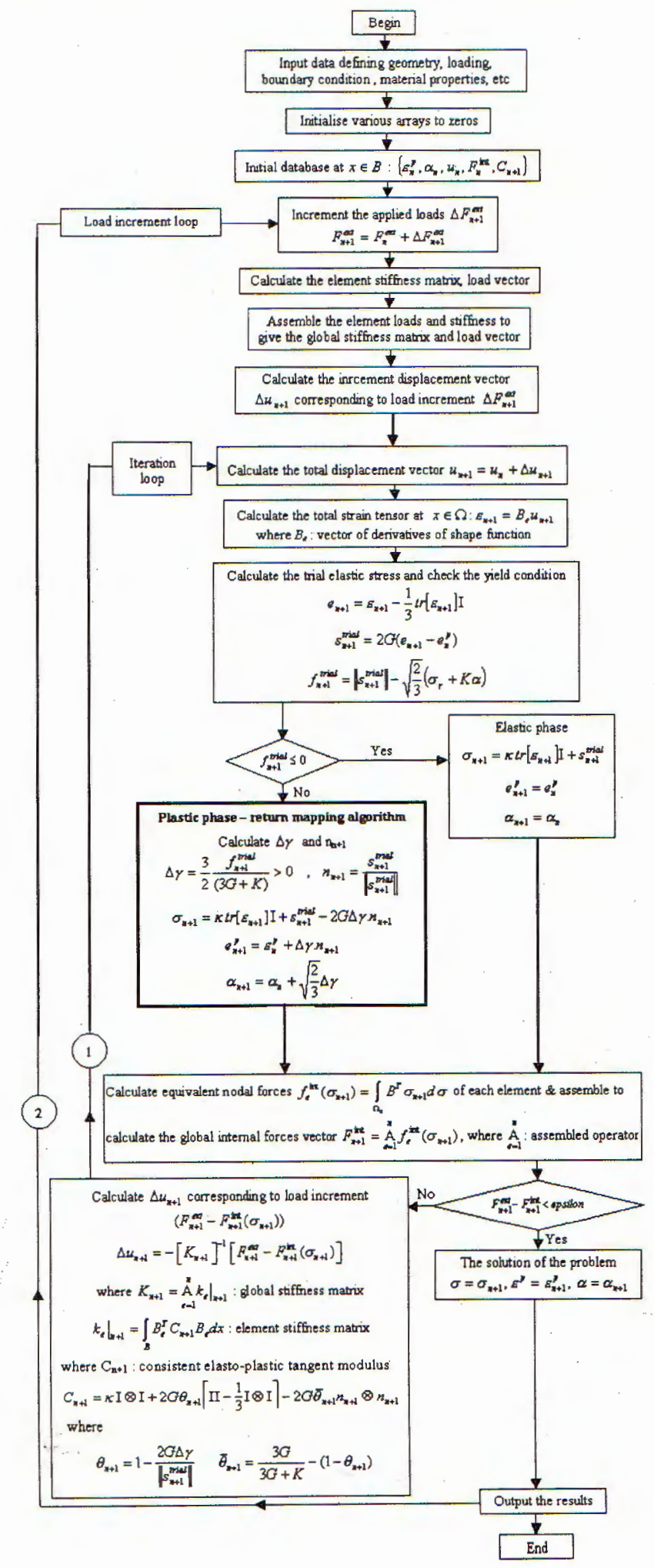




\section{NUMERICAL SIMULATION}

\subsection{Thick cylinder subjected to an internal pressure}

The problem concerned with a thick cylinder has an analytical solution represented in $[1],[4]$.

The thick cylinder has internal radius $a=0.1 \mathrm{~m}$, external radius $b=0.2 \mathrm{~m}$, Young's modulus $E=21000 \mathrm{kN} / \mathrm{m}^{2}$, and Poisson's ratio $\nu=0.3$. Von Mises criterion is used with a yield stress $\sigma_{\gamma}=24 \mathrm{kN} / \mathrm{m}^{2}, c$ is the yield radius (Fig. 3). The internal pressure p varies between $8 \mathrm{kN} / \mathrm{m}^{2}$ and $20 \mathrm{kN} / \mathrm{m}^{2}$, this value is corresponding to the total plastification of the cylinder and its failure. Because of the symmetric characteristic of the problem, we only calculate for a quarter of cylinder. A 715-triangle-element mesh (Fig. 4) has been used for the plane strain analysis.

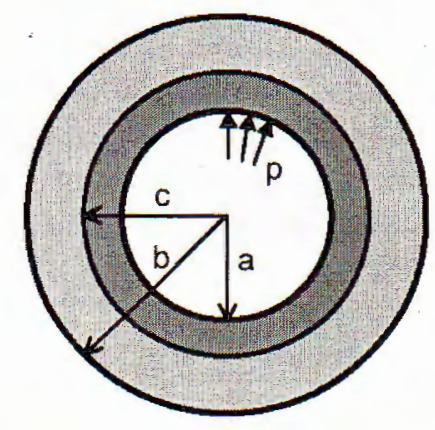

Fig. 3. The thick cylinder under the internal pressure
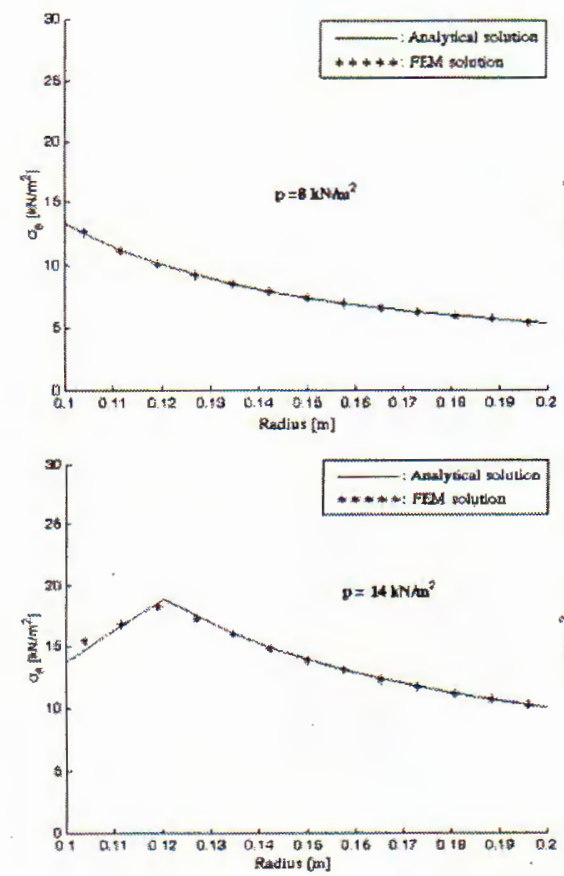



Fig. 4. The FEM element mesh of $\frac{1}{4}$ of cylinder (715 triangle elements)
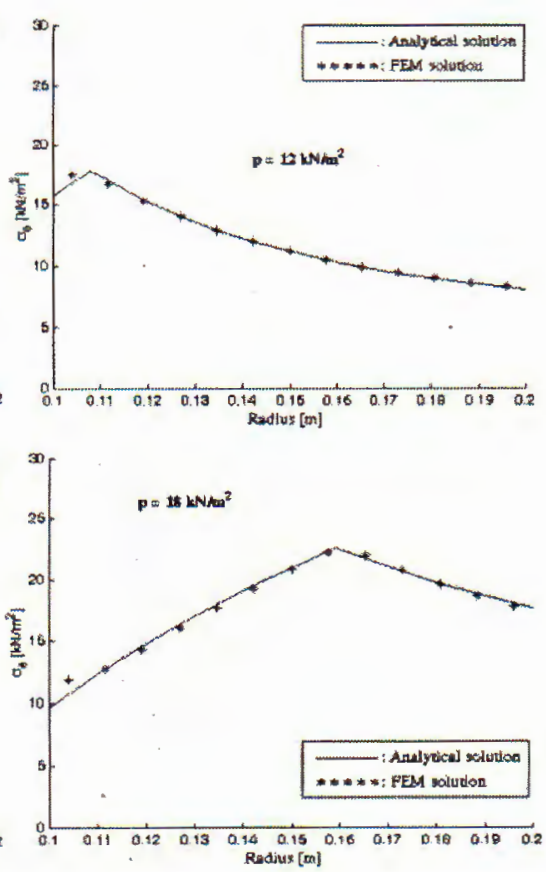

Fig. 5 The diagram of circumferential stresses $\sigma_{\theta}$ corresponding to perfectly plastic case

$$
(K=0) \text { at } p=8 \mathrm{kN} / \mathrm{m}^{2}, p=12 \mathrm{kN} / \mathrm{m}^{2}, p=14 \mathrm{kN} / \mathrm{m}^{2}, p=18 \mathrm{kN} / \mathrm{m}^{2}
$$


First, we present the expression of circumferential stresses $\sigma_{\theta}$ corresponding to perfectly plastic case (hardening modulus $K=0$ ) at $p=8 \mathrm{kN} / \mathrm{m}^{2}, p=12 \mathrm{kN} / \mathrm{m}^{2}, p=14$ $\mathrm{kN} / \mathrm{m}^{2}, p=18 \mathrm{kN} / \mathrm{m}^{2}$ (Fig.5). Then we present the radial stress $\sigma_{r}$ corresponding to perfectly plastic case $(K=0)$ at $p=14 \mathrm{kN} / \mathrm{m}^{2}$ (Fig.6). On the Fig. 5, the yield radius develops from the inner radius to the position of the tip of diagrams. This yield radius develops gradually from inside to outside corresponding to the increasing of inner pressure. To be able to understand the process of formation and development of the yield radius, we need consider both diagrams of circumferential and radial stress. The yield radius will be formed and developed when $\sigma_{\theta}-\sigma_{r}=2 k, k=\sigma_{\gamma} / \sqrt{3}$. This is the von-Mises yield criterion (Fig. 5 and Fig.6). For the material having hardening modulus $K>0$, as expected on the Fig. 7, the yield radius develops more slowly as $K$ increases. This is quite suitable with the theory, because the material having hardening modulus $K>0$ will have the elastic modulus increased when the material reachs the flow stress $\sigma_{\gamma}$ and the process of loading continues. The bigger the material has the hardening modulus $K$, the bigger the elastic modulus is increased. We compare the evolution of the yield radius $\mathrm{c}$ corresponding to 4 cases: a) analytical solution $(K=0)$, b) FEM solution with perfectly plastic case $K=0$, c) FEM solution with hardening modulus $K=E / 3=7000 \mathrm{kN} / \mathrm{m}^{2}$, d) FEM solution with hardening modulus $K=2 / 3 E=14000 \mathrm{kN} / \mathrm{m}^{2}$ (Fig. 7).

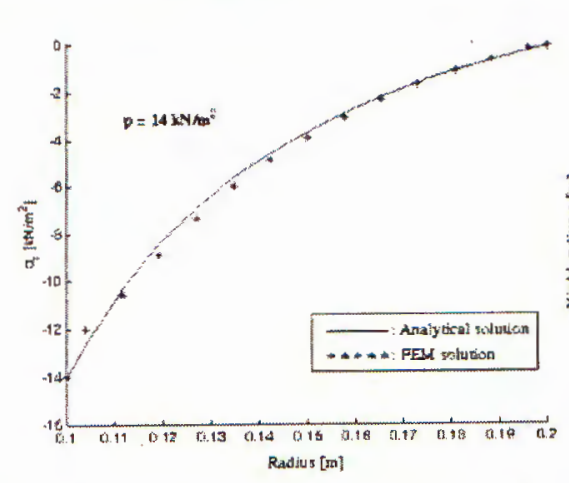

Fig. 6. Radial stress $\sigma_{r}$ corresponding to plastic case $(K=0)$ at $p=14 \mathrm{kN} / \mathrm{m}^{2}$

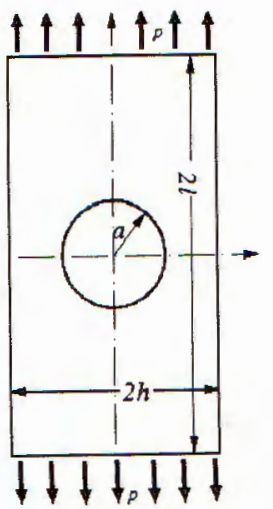

Fig. 8. Strip with a circular hole

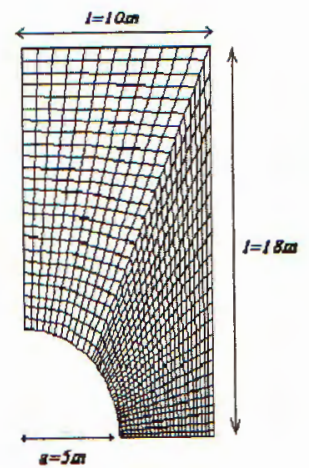

Fig. 9. Plane -strain strip with a circular

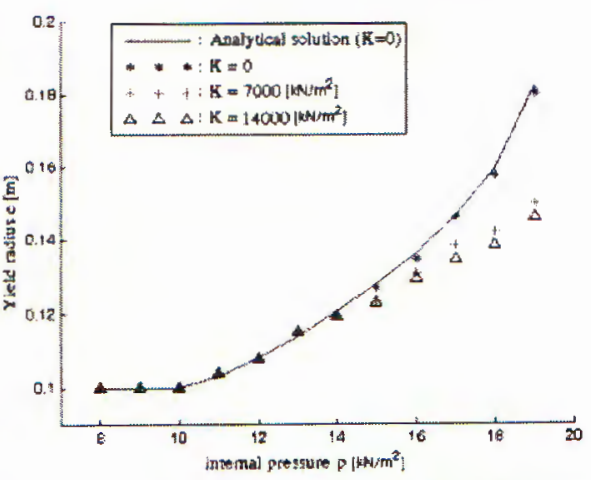

Fig. 7. Yield radius corresponding to perfectly $p$ varies between 8 and $19 \mathrm{kN} / \mathrm{m}^{2}$

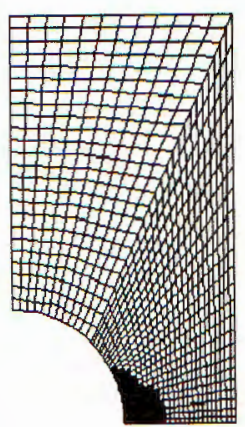

Fig. 10. Plastic domain $(K=0, P=$ $120 \mathrm{kN} / \mathrm{m}$ )

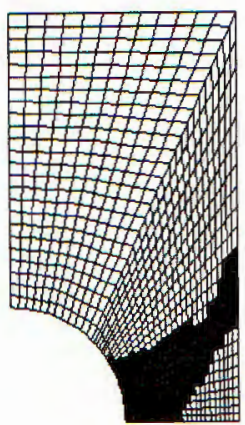

Fig. 11. Plastic domain $(K=0, P=$ $137.5 \mathrm{kN} / \mathrm{m}$ ) 


\subsection{Rectangular strip with a circular hole subjected to an extension}

The geometry in considered problem is shown in Fig. 8. The elastic properties of the material are taken as $E=21000 \mathrm{kN} / \mathrm{m}^{2}, \nu=0.3$. The yield stress $\sigma_{\gamma}=24 \mathrm{kN} / \mathrm{m}^{2}$. Because of symmetry the symetry of the problem, only $1 / 4$ of the strip is analyzed. A 864 quadrilateral - element mesh (Fig.9) is employed in the calculation for the plane stress analysis.

The solution of elastic-plastic problem is very complex on mathematics, with supposition of rigid-plasticity and using slip line method in one deseribed describe the expansion of plastic domain and computed the exact value of limited loading $P_{*}=4 k(h-a)=282$ $\mathrm{kN} / \mathrm{m}$.

In this paper, once more we use the algorithm return - mapping and obtain the expansion of plactic domain when we increase loading and compute approximate limited loading value $P_{*}=275 \mathrm{kN} / \mathrm{m}($ error $<3 \%)$.

Figures 14,15 describe the dependence of cirumferential stress $\sigma_{\theta}$ and radial stress $\sigma_{r}$ upon radius $r$. At plastic radius, the von-Mises criterion is satisfied. In comparison figures 10,11 with figures 12,13 , we regconize that, in isotropichardening case, the platic domain develops slower than in perfectlyplastic case. This results can be predicted. The computational limitedloading is suitable to the exact value.

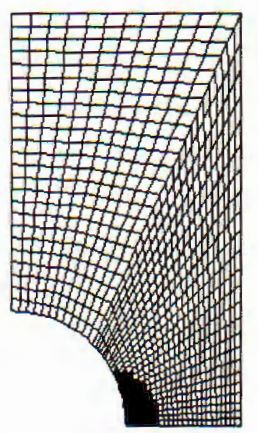

Fig. 12. Plastic domain Fig.13. Plastic domain $(\mathrm{K}=10500, \mathrm{P}=120 \mathrm{kN} / \mathrm{m}) \quad(\mathrm{K}=10500, \mathrm{P}=152 \mathrm{kN} / \mathrm{m})$

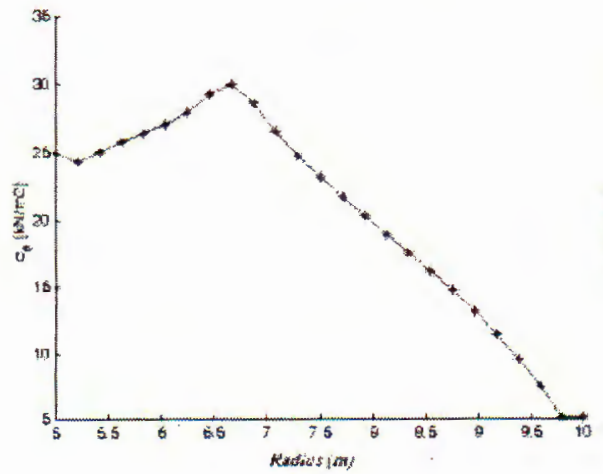

Fig. 14 The diagram of circumferential stresses $\sigma_{\theta}$

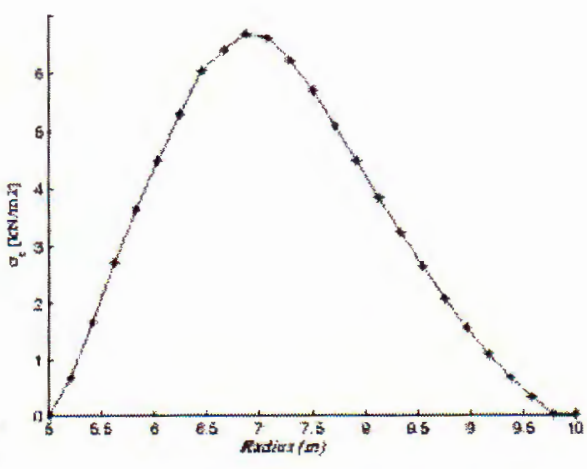

Fig. 15. Radial stress $\sigma_{r}$

\section{CONCLUSION}

The numerical solution of the two-dimensional problems by the return mapping algorithm is suitable with the isotropic hardening elastic-plastic theory. One drawback of this algorithm is not to consider the Baushinger characteristic that the center of the yield 
surface experiences a motion in the direction of the plastic flow. This characteristic will be researched with the kinematic isotropic hardening elastic-plastic theory. Besides, this algorithm will be also developed for the material having non-linear isotropic hardening law.

We thank to M.Sc. Nguyen Xuan Hung who gave the value ideas in the process of calculating the numerical solutions.

This paper is implemented with the financial support of the basic research project from the Vietnam National Council for Natural Sciences.

\section{REFERENCES}

1. Dao Huy Bich, Plasticity Theory and Applications, Construction Press, 2004 (in Vietnamese).

2. D. R. J. Owen, E. Hinton, Finite Elements in Plasticity, Pineridge Press Limited Swansea U.K, 1980.

3. J. C. Simo, T. J . R. Hughes, Computational Inelasticity, Springer, 1998.

4. Kachanop, The Basic of Plasticity Theory, College and Secondary School Press, Hanoi, 1977 (in Vietnamese).

5. Nguyen Thoi Trung, Ngo Thanh Phong, Nguyen Phu Vinh, "Numerically solving the one-dimension elasto-plastic problem by return mapping algorithm", Science and Technology Development Jourmal - VNU-HCMC 7 (1) (2004) (in Vietnamese).

6. R. Glowinski, J. L. Lions, R. Tremolieres, Analyse Numerique des Inequations Variationnelles, Tome 1: Theorie Generale - Premieres Applications, Tome 2: Applications aux Phenomenes Stationnaires et D'evolution, Dunod, Paris, 1976.

Received May April 10, 2005

Revised August 12, 2005

\section{VỀ MộT PHƯƠNG PHÁP GẦN ĐƯNG GIẢI BÀI TOÅN BIÊN TRONG VẬT THỂ RẮN ĐÀN-DÉO TÁI BỀN ĐĂNG HƯớNG}

Bài toán trình bầy lý thuyết, mô hình, dạng yếu, phương pháp phần tử hữu hạn và giải thuật ánh xạ quy hồi cho bài toán đàn dẻo tải bền đẳng hướng. Giải thuật được áp dụng để mô phỏng số một số bài toán biến dạng phẳng. 